\title{
Assessment of the Effect of Information Access on Emotional Well-Being of the Elderly in Ibadan
}

Oluwagbemiga Oyinlola* and Oluwafunmilayo O Folaranmi

Department of Social Work, University of Ibadan, Ibadan, Nigeria

*Corresponding author: Oluwagbemiga Oyinlola, Department of Social Work, University of Ibadan, Ibadan, Nigeria, Tel: 2347031263579; E-mail: oluwagbemiga.oyinlola@yahoo.com

Rec date: Apr 01, 2016; Acc date: Apr 26, 2016; Pub date: Apr 28, 2016

Copyright: ( 2016 Oyinlola $\mathrm{O}$, et al. This is an open-access article distributed under the terms of the Creative Commons Attribution License, which permits unrestricted use, distribution, and reproduction in any medium, provided the original author and source are credited.

\begin{abstract}
The objective of the study is to assess the effect of information access on emotional well-being among the elderly presented at the Geriatric Center, University College Hospital, Ibadan.

The study used a descriptive survey research to retrieve information from the purposively selected 186 respondents attending the Geriatric Centre. Structured questionnaire was used to retrieve information from the respondents after obtaining ethical approval from the hospital research ethics committee.

The result was analysed using Analysis of Variance (ANOVA) which revealed that, there was a significant effect of print media on the emotional well-being of the elderly at the Geriatric Center, University College Hospital, Ibadan. Internet access had significant effect on the emotional well-being of the elderly at the Geriatric Center, University College Hospital, Ibadan. Also, access to audio-visual had significant effect on the emotional well-being of the elderly at the Geriatric Center, University College Hospital, Ibadan. The multiple regression analysis showed that, audio-visual contributed the most to the emotional well-being of the elderly $(\beta=0.402 ; t=6.788 ; p<0.05)$. Followed by Print-media $(ß=0.216 t=5.150 ; p<0.05)$ and then by Internet access $(ß=0.211 t=2.300 ; p<0.05)$.

Recommendations include development of age appropriate production of adult friendly Information Education Communication (IEC) materials. Specialized training in communication skills for Geriatric medical social workers, nurses and physicians to flexibly work in a culturally sensitive environment will enhance promotion dignity and worth of elderly patients presented in hospitals.
\end{abstract}

Keywords: Information access; Print media; Internet access; Audiovisuals; Emotional well-being; Elderly

\section{Introduction}

The current trend of care for the elderly have indicated that there is a definite need to 'bridge the gap' between elderly users and their accessibility to information in developing countries especially subSahara Africa. Burton and Brown [1] asserted that the growing the 'digital divide' is a concern for developed countries and as led to a number of initiatives being employed to encourage information usage for the older generation and to ensure they are not excluded from the digital world. However, inspite of the concern about care for the elderly, reports have indicated that developed countries like UK uses information gotten/internet in controlling their finances, keeping upto-date with current affairs and staying contact with their family and friends. Hence, accessibility to relevant information could serve as a veritable/valuable tool in reducing the risk of social exclusion, a concern that many of the elderly face. The elderly are very likely to develop age related impairment such as visual and auditory impairment or immobility related disability accessibility to information then becomes seriously difficult and then becomes an important consideration for policy makers, social worker, doctors, nurses and other health care professionals in the country.
There is the need to note that the increasing and improving individual based information access for the elderly tends encourage the elderly to be more updated with current affairs, participate constructively to National Development, address the social isolation, depression and other psychosocial problems attached to the elderly. Adeleke [2] buttressed that, type of information has the potential to help the elderly to address impeding social and psychological problem depression and isolation to innovatively participate to countries needs from their wealth of wisdom.

Wicks, [3] opined that, the elderly rely on interpersonal sources together with internally-produced print materials for their information needs regarding participation in community clubs and organizations. He explains further that, the elderly sought printed resources for hobby-related information seeking.

Campbell and Nolfi, [4] opined that, for answers to medical and psychosocial questions, they tended to look primarily to interpersonal sources. Interpersonal sources include geriatric professionals, family members, friends and other professionals. The same study revealed that, elderly adults were willing to use the internet as a starting point for general health information, but when it came to making informed decisions about their health care, the majority adhered to a physiciancentered care model [5].

Omokaro and Emem [6] opined that, information is sought from different sources depending on the nature of information needs. Media 
Page 2 of 5

sources are often the most common ones, and television plays a significant role in providing health and social information for the elderly. Other studies have shown on the contrary that, printed media are the most prevalent sources of information and the most common source of information for the elderly due to the increasing number of print-media agencies in the country. Okoye [7] found out that the elderly are engaged in serious and thought provoking discussion with the young generations on socio-political uses in the country, these as a result have proven to have addressed the social isolation of the elderly. Rees and Bath [8] discovered that, printed media as a major source of information-seeking on health for the elderly may include: reading medical books, journals, leaflets from organisations, magazines and newspaper. The internet is also becoming a more commonly used source of information for the elderly. It is not surprising that, surveys have indicated that, eight (8) in ten (10) adult American going online had searched for information about their health (BBC, [9] ).

The aim of this study is to examine the effect of information access on emotional well-being of the elderly presented at the Chief Tony Anenih Geriatric Centre, University College Hospital, Ibadan.

\section{Methods and Materials}

\section{Population}

Descriptive research design was for the study. The population comprises of elderly patients attending Chief Tony Anenih Geriatric Centre, University College Hospital Ibadan, who are within the ages of 60years and above. The Chief Tony Anenih Geriatric Centre (CTAGC), University College Hospital, Ibadan is First Geriatric Centre in West African Sub-Region, established in November, 2012

\section{Sampling Method}

The study randomly selected 186 registered patients of CTAGC to participate in the study for a period of two (2) months during their meeting days

\section{Participant}

Eligible respondents were registered patients of CTAGC, UCH, Ibadan. The researcher briefly interviewed potential respondents to determine whether they were competent, judge their ability to understand the psycho-social problems surrounding poor information access. Informed consent was obtained from the patient and ethical approval for the study and was granted by the Hospital Research Ethics Committee, University College Hospital (UCH)/University of Ibadan (UI).

\section{Data collection}

The main instrument used for the research was the questionnaire tagged 'Information Access and Emotional Well-being Questionnaire' (IAEWQ). The questionnaire was designed on a Two (2) scale Yes (1) No(2). The self-structured questionnaire was made-up of four (4) section viz A-C. Section A consisted of item questions that measured age, religion, level of education and presenting illness or disabilities of the elderly patients, Section B measured information access which consist of five (5) items relating to accessibility to print media, internet access and audio-visuals. Section C measured Emotional Well-being was developed to measure Emotional Well-being Scale (EWS) Wachs and Cordova, [9]. Furthermore, the researcher participated and served as an observer in the meeting of Elder's Forum, UCH, Ibadan for a period of two (2) months.

\section{Data Analysis}

Data analysis was done at the univariate, bivariate and the multivariate levels. The simple percentages and frequency count was used to analyse the demographic section while ANOVA was used to assess the effect of information access on the emotional well-being of the elderly in Ibadan. The result was analysed with Statistical Package of Social Sciences (SPSS version 20).

\section{Results}

\begin{tabular}{|c|c|c|}
\hline & Male & Female \\
\hline & $66(35.5 \%)$ & $120(64.5 \%)$ \\
\hline \multicolumn{3}{|l|}{ Age } \\
\hline 60-65years & $31(46 \%)$ & $64(53.3 \%)$ \\
\hline 66-70years & $10(15.2 \%)$ & $22(18.3 \%)$ \\
\hline 71-75years & $23(34.8 \%)$ & $14(11.7 \%)$ \\
\hline 76-84years & $2(3.0 \%)$ & $15(12.5 \%)$ \\
\hline 85years and above & $0(0 \%)$ & $5(4.2 \%)$ \\
\hline \multicolumn{3}{|l|}{ Religion } \\
\hline Christianity & $42(63.6 \%)$ & $81(67.5 \%)$ \\
\hline Islamic & $20(30.3 \%)$ & $14(11.6 \%)$ \\
\hline Traditional/other religion & $4(6.1 \%)$ & $25(20.8 \%)$ \\
\hline \multicolumn{3}{|l|}{ Level of education } \\
\hline No formal education & $10(15.2 \%)$ & $29(24.2 \%)$ \\
\hline Primary school education & $7(10.6 \%)$ & $43(35.8 \%)$ \\
\hline Secondary school education & $21(31.8 \%)$ & $15(12.5 \%)$ \\
\hline Post-secondary education & $28(42.4 \%)$ & $33(27.5 \%)$ \\
\hline \multicolumn{3}{|l|}{ Presenting illness/Disability } \\
\hline Hearing impairment & $2(3 \%)$ & $15(12.5 \%)$ \\
\hline Visual impairment & $0(0 \%)$ & $41(34.2 \%)$ \\
\hline Difficulty in mobility & $26(39.4 \%)$ & $20(16.7 \%)$ \\
\hline Cognitive impairment & $10(15.2 \%)$ & $7(5.8 \%)$ \\
\hline Other illnesses/disabilities & $28(42.4 \%)$ & $37(30.8 \%)$ \\
\hline
\end{tabular}

Table 1: Demographic characteristics of respondents by sex.

Based on the results presented on the demographic characteristics of respondents who are registered members of the elders' forum of CTAGC, UCH, Ibadan. More than half of the respondents are female $120(64.5 \%)$ while $66(35.5 \%)$ of the respondents are male (Table 1$)$. Over $34.8 \%$ of the male respondents are within the ages of $71-75 y$ years while $53.3 \%$ of the elderly among the female respondents are within the ages of 60-65years. 
This is an indication that, more women within the ages of 60-65years are engaged in recreational activities in Ibadan as a result of disengagement from the workforce, or the urge to meet people of the same age circle. $42(63.6 \%)$ of the male respondents are Christians by faith while $81(67.5 \%)$ of the female respondents are also Christians while less than $25 \%$ of the male respondent practice the traditional or belief in other religion.

In terms of the level of education of the respondents, more than half of the male respondents $28(42.4 \%)$ had post-secondary education while from the female respondents, 43 (35.8\%) of the respondents had primary school education. This indicates that, 20 of 50 respondents that participated in the study had post-secondary education.

$28(42.4 \%)$ are presented with other form of illness and disabilities, while $39.4 \%$ are presented with difficulty in mobility which are in different forms among male while $34.2 \%$ among female are presented with visual impairment which have a significant effect on their choice of information even to their accessibility to information.

Hypothesis 1: Print-media has no significant effect on emotional well-being of the elderly in Ibadan.

\begin{tabular}{|c|c|c|c|c|c|c|}
\hline Variables & Yes & No & f-cal & f-crit & p & Remark \\
\hline Magazines & $31(24.6 \%)$ & $13(21.7 \%)$ & \multirow[t]{5}{*}{32.506} & \multirow[t]{5}{*}{2.19} & \multirow[t]{5}{*}{0.002} & \multirow[t]{5}{*}{ Sig } \\
\hline Newspapers & $38(30.2 \%)$ & $24(40 \%)$ & & & & \\
\hline $\begin{array}{l}\text { Tracks } \\
\text { messages }\end{array}$ & $23(18.3 \%)$ & $11(18.3 \%)$ & & & & \\
\hline Books & 25 (19.8\%) & $8(13.3 \%)$ & & & & \\
\hline $\begin{array}{l}\text { Others print } \\
\text { medias }\end{array}$ & $9(7.1 \%)$ & $4(6.7 \%)$ & & & & \\
\hline
\end{tabular}

(f-cal $2.19=32.506, p<0.002$ )

Table 2: ANOVA result showing the effect of Print-media on emotional well-being of the elderly in Ibadan.

The Table 2 showed that, over $24 \%$ of the elderly patients uses magazine as source of information through the print media, less than $30 \%$ of the respondents uses the newspaper, $18.3 \%$ of the respondents uses the track massages as a source of print medias, over 19\% uses books as a source of print media and $7.1 \%$ uses other sources of print medias.

The result is supported with the hypothesis that, print media had significant effect on the emotional well-being of the elderly at Geriatric Centre, University College Hospital, Ibadan (f-cal2.19= 32.506> $\mathrm{p}<0.002)$.

Hypothesis 2: Audio-visuals has no significant effect on emotional well-being of the elderly in Ibadan.

\begin{tabular}{|l|l|l|l|l|l|l|}
\hline Variables & Yes & No & f-cal & f-crit & p & Remark \\
\hline $\begin{array}{l}\text { I have access to } \\
\text { computer with } \\
\text { internet at home }\end{array}$ & $22(27.2 \%)$ & $12(11.4 \%)$ & 3.789 & 2.19 & 0.001 & Sig \\
\hline $\begin{array}{l}\text { I have access to } \\
\text { computer without } \\
\text { internet at home }\end{array}$ & $10(12.3 \%)$ & $42(40 \%)$ & & & & \\
\hline
\end{tabular}

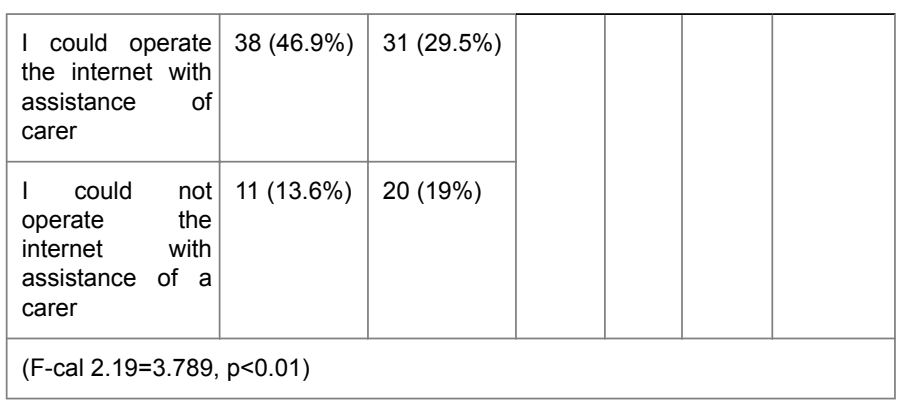

Table 3: ANOVA result showing the effect of Internet access on emotional well-being of the elderly in Ibadan.

Based on the results shown above, $27.2 \%$ of the respondents have access to compute with internet at home, $40 \%$ of the respondents have computer without internet, more than $46 \%$ responded that, they could operate the internet with assistance of their carer while about $19 \%$ they could operate the internet with the assistance of a carer (Table 2).

However, the result the findings is supported by the hypothesis which states that, there is an effect of internet access on the emotional well-being of the elderly Geriatric Centre, University College Hospital, Ibadan.

The results revealed that, $\mathrm{f}$-ratio is greater than the $\mathrm{f}$-table $(\mathrm{f}-\mathrm{cal}=$ $3.789>\mathrm{f}=\mathrm{crit}=2.19, \mathrm{p}<0.05)$.

Hypothesis 3: Audio-visuals has no significant effect on emotional well-being of the elderly in Ibadan.

\begin{tabular}{|c|c|c|c|c|c|c|}
\hline Variables & Yes & No & f-cal & f-crit & $\mathbf{p}$ & Remark \\
\hline Radio & 41 (51.9\%) & 55 (51.4\%) & \multirow[t]{4}{*}{8.872} & \multirow[t]{4}{*}{2.19} & \multirow{4}{*}{$\begin{array}{l}0.00 \\
1\end{array}$} & \multirow[t]{4}{*}{ Sig } \\
\hline Television & $31(39.2 \%)$ & $15(14 \%)$ & & & & \\
\hline Simulations & $4(5.1 \%)$ & $23(21.5 \%)$ & & & & \\
\hline $\begin{array}{l}\text { Other audio } \\
\text { visual } \\
\text { sources }\end{array}$ & $3(3.8 \%)$ & $14(13.1 \%)$ & & & & \\
\hline (F-cal 2.19= & $72, p<0.05)$ & & & & & \\
\hline
\end{tabular}

Table 4: ANOVA result showing the effect of access to audio-visual on emotional well-being of the elderly in Ibadan.

Based on the result presented above, more than $51 \%$ of the respondents uses radio in their houses, while more than $39 \%$ uses television as their information source, while over $21 \%$ of the respondents does not use simulations while more than $13 \%$ uses other audio-visual sources for their information (Table 4).

The result is in tandem with the result of the research hypothesis which revealed that, there is a significant effect of access to audiovisual on the emotional well-being of the elderly at Geriatric Centre, University College Hospital, Ibadan.

The results revealed that, $f$-ratio is greater than the f-table ( $\mathrm{f}$ cal2.19=8.872 $>\mathrm{f}=$ crit $=, \mathrm{p}<0.05)$.

Hypothesis four: There is no relative joint effect of access to print media, internet facilities and audio-visuals on the emotional well-being of the elderly at the Geriatric Center, University College Hospital, and Ibadan. 


\begin{tabular}{|c|c|c|c|c|c|c|}
\hline \multicolumn{7}{|l|}{ ANOVA } \\
\hline & $\begin{array}{l}\text { Sum of } \\
\text { Squares }\end{array}$ & df & $\begin{array}{l}\text { Mean } \\
\text { Squar } \\
\text { e }\end{array}$ & f & $\begin{array}{l}p- \\
\text { value }\end{array}$ & Remark \\
\hline Regression & 231.551 & 6 & 61.011 & 11.552 & $<0.002$ & \multirow{3}{*}{$\begin{array}{l}\text { Significar } \\
t\end{array}$} \\
\hline Residual & 332.913 & 183 & 6.941 & & & \\
\hline \multirow[t]{3}{*}{ Total } & 1114.91 & 186 & & & & \\
\hline & \multicolumn{2}{|c|}{$\begin{array}{l}\text { Unstandardized } \\
\text { Coefficients }\end{array}$} & \multicolumn{2}{|c|}{$\begin{array}{l}\text { Standardized } \\
\text { Coefficients } \\
\text { Beta }\end{array}$} & $\begin{array}{lll}T \\
\end{array}$ & $p$-value \\
\hline & B & Std. Error & & & & \\
\hline (Constant) & 12.821 & 2.155 & & & 14.537 & 0.002 \\
\hline Print Media & 0.216 & 0.946 & 0.137 & & 5.15 & $<0.01$ \\
\hline $\begin{array}{l}\text { Internet } \\
\text { access }\end{array}$ & 0.211 & 0.613 & 0.239 & & 2.3 & $<0.01$ \\
\hline $\begin{array}{l}\text { Audio- } \\
\text { visuals }\end{array}$ & 0.402 & 0.592 & 0.609 & & 6.788 & $<001$ \\
\hline $\begin{array}{l}\mathrm{R}=0.597, \\
\text { Estimate }=1 .\end{array}$ & $\begin{array}{l}\text { quare }=0 . \\
8\end{array}$ & 56, Adjust & $\mathrm{R} s q$ & $\mathrm{are}=0$ & 34, Std. E & rror of the \\
\hline
\end{tabular}

Table 5: Multiple Regression Analysis showing joint effect of print media, internet facilities and audio-visuals on the emotional well-being of the elderly.

The table presented above in Table 5 showed the combination of the independent variables (print media, internet access and audio-visuals) account for $35.6 \%$ of the variance in emotional well-being (R2 adjusted $=0.334$ ). The analysis of variance of the multiple regression data yielded an F-ratio value which was found to be significant at 0.05 alpha level $(\mathrm{F} 2.19=11.552 ; \mathrm{p}<0.01)$. However, results obtained in table $4 \mathrm{~b}$ above indicate the effect of each of the independent variables (print media, internet facilities and audio-visuals) on the dependent variable (emotional well-being). In terms of most significant effect, AudioVisual contributed most to the emotional well-being of the elderly $(\beta=0.402 ; t=6.788 ; p<0.01)$. Next in terms of magnitude of effect is Print-media $(B=0.216 t=5.150 ; p<0.01)$ and then by Internet access $(\beta=0.211 \mathrm{t}=2.300 ; \mathrm{p}<0.01)$ Hence, all the three (3) assessment of internet access (print-media, internet facilities and audio-visual) made significant effect on emotional well-being of the elderly at the Geriatric Center, University College Hospital, Ibadan but, internet access had the least significant effect.

\section{Discussion}

There was a significant effect of the print media on the emotional well-being of the elderly in Ibadan. The result of the findings is in tandem with the findings of Help Age International, [10] that exposing the elderly to reading of newspapers, magazines/articles and journal tends to revive the spirit of quest for knowledge in the elderly even with their disabilities or diseases. Similarly, Sarni, [11] opined that, elderly patients without any visual impairments tends to provide constructive answers to national problems when exposed to print media in a recreational day care facilities.

There was a significant effect of Internet access on the emotional well-being of the elderly in Ibadan. The result is in contrary with the findings of Escamilla, [12] that internet access may not be able to help the elderly when they are already hospitalized, but it could be a useful resource to help them before they enter the hospital or guide their carer on information affecting the elderly. Furthermore, Campbell and Nolfi, [13] maintained that exposing seniors to Internet access is based on practice guidelines and standards of care which should increase the probability that they will receive the proper treatment and take preventive measures. The same study showed the discrepancy in internet use among age groups decreases each year, a large gap exists between seniors who frequently use the Internet to find health care information than those who do not [14].

The result also showed that, there was a significant effect of Audiovisual facilities on the emotional well-being of the elderly in Ibadan. The result is supported by the findings of Mirowsky and Ross, [15] that, accessibility of elderly patient to audio-visual materials like television and radio enhances recovery from illness as this serves as a form diversionary therapy. Additionally, Chow, [16] opined that, provision of televisions and radio in hospital wards and clinics enables the elderly patients to engage in educative discussion with their peers which aid their social and emotional recovery.

All the three (3) assessment of information access (print-media, internet facilities and audio-visual) had significant effect on emotional well-being of the elderly in Geriatric Center, University College Hospital, Ibadan but, internet access had the least significant effect. The result of findings is supported by Laurich, [17] adults age 65 and over do not appear to be using the Internet due to the frailty condition attached to old age. This population has resisted going online, but all age groups have begun to gain ground as users Laurich maintains that the elderly believe the Internet does not contain information highly relevant to their needs. Moreover, more than any other age group, they tend not to have Internet access either in their home or at work, though they do use the Internet at libraries.

Togonu-Bickersteth, [18] corroborated that, the social dimensions of care for the elderly through improved information and communication strategies has not allowed accessibility to internet facilities to take its place in the emotional recovery of the elderly. She however suggests that, provision of comprehensive information services (reading of newspaper, electronic system of communication with the care professionals, chatting with friends and relations afar-of through the internet) have a great significant influence on their general well-being) because, it was perceived that, they feel loved and their sense of belonging is however socially restored. In the same study, provision of emergency call services for the elderly who are diagnosed with terminal illnesses and also on life support in care centers for the elderly will enhance quick and prompt action to care.

Furthermore, Help Age International, [19] addressed the issue related to information needed by the elderly as it serve as a source of economic development. It was perceived that, rural areas are traditionally conservative and can be both unfriendly to outsiders and for new ideas. The typical rural library is perceived by Help Age international as primarily a place of books. It was recommended that, the rural librarian and their staffs have an important role to play as a stimulant for aged people to develop their intellects through library resources.

\section{Conclusion}

As the population of the aged increases, there is no safety net in place for most Nigerians through information accessibility (Aboderin, 
Citation: Oyinlola O, Folaranmi OO (2016) Assessment of the Effect of Information Access on Emotional Well-Being of the Elderly in Ibadan. J

Page 5 of 5

[20]). From the study it is an indication that, the elderly are bereaved of information and there are relatively limited information-acquiring opportunities for the ageing population due to unfavourable social and political system. The study recommends that, NGOs, CBOs and FBOs should develop age appropriate information access for the elderly to keep them updated to situations around them and to also serve as platform for them to contribute innovatively to developmental issues in the country. There is need for health professionals in hospitals to produce age sensitive Information Education Communication (IEC) that would keep the elderly of information they need to keep them going in life as a citizen. It is also important that, policy makers should expedite action in the production and development of Policy on care for the elderly. There is need for physicians, nurses and medical social workers to cultivate specialized training in communication skills among older adults in a culturally sensitive environment as they work with the elders, their families, and the casework for the frail and disabled elderly in the community

\section{References}

1. Burton RR, Brown JS (1982) An Investigation of Computer Caching for Informal Learning Activities. Intelligent Tutoring Systems 79-98.

2. Adeleke RO (2004) Caring for the Elderly in a Resource Constraint Environment. Quarterly Ground Round, Ibadan.

3. Wicks DA (2004) Older Adults and their information seeking. Journal of Behavioral and Social Sciences Librarian 2: 1-26.

4. Campbell R, Nolfi D (2005) Teaching adults to use the Internet to access health care information: before-after study. Journal of Medical Internet Resources 13: 23-37.

5. Emem O (2008) Some Non-Cultural Determinants of Adult Children Care of Elderly Parents. Proceedings of the 1st Conference of Stakeholders on Care of the Elderly in Nigeria. Pub. A.A. Communications Calabar-Nigeria.

6. Okoye UO (2013) Community Based Care for Home Bound Elderly Persons In Nigeria; A policy Option. International Journal of Innovative Research in Science Engineering and Technology 2: 7086-7089.
7. Rees D, Bath K (2000) Social Network Interaction and Mortality: A six Year Follow-up Study of Random Sample of the Swedish Population. Journal of Chronic Diseases 40: 10-16.

8. BBC News Online (2003) Digital divide sees elderly left behind.

9. Wachs UL, Cardova YS (2007) Emotional Well-being Scale. Journal of Emotional Adjustment 5: 34-113.

10. HelpAge International (2004) Age and security. How social pensions can deliver effective aid to poor older people and their families London.

11. Sarni U (2013) Culture and social support: Who seeks it and why?. Journal of Personality and Social Psychology 87: 354-62.

12. Escamilla YL (2006) Health Problem of the elderly Nigerians. Social Science and Medicine 24: 885-887.

13. Campell R, Nolfi D (2005) Teaching adults to use the Internet to access health care information: before-after study. Journal of Medical Internet Resources 13.

14. Mirowsky J, Ross CE (2009) Age and the Sense of Control. Social Psychology Quarterly 58: 31-43.

15. Chow OO (2013) Ageing and Modernization: A revision of the Theory. Late Life Communities and Environmental Policies 123-146.

16. Laurich R (2000) The platinum web: sites dedicated to senior citizens on the Internet. Collection Building 21: 174-182.

17. Togonu-Bickersteth F (1998) Challenges of Providing and delivering social services, contribution to the United Nation Expert Workshop on Innovation in Delivery and Financing of Social Services 13-16.

18. Help Age International/Institute for Development Policy and Management (2003) Non-contributory pensions and poverty prevention. A comparative study of South Africa and Brazil. London.

19. Oyinlola O (2014) Effect Social Support on the psychosocial well-being of the elderly in Old peoples home in Ibadan. Unpublished Masters of Social Work Thesis.

20. Aboderin I (2006) Intergenerational Support and Old Age in Africa. Transaction Publisher 13: 978- 207. 